\title{
Perscrutando Diários de Aulas e Produzindo Narrativas sobre a Disciplina Estágio Supervisionado de um Curso de Licenciatura em Matemática*
}

\author{
Peering into Class Diaries and Writing Narratives about the Teaching \\ Internship Course in a Preparation of Mathematics Teachers Program
}

\author{
Marcos Antonio Gonçalves Júnior ** \\ Dione Lucchesi de Carvalho**
}

\begin{abstract}
Resumo
De 2008 a 2010, recebi alunos de um curso de licenciatura, que cursavam o Estágio Supervisionado II, em minhas aulas de Matemática, supervisionando-os e orientando-os em seu Trabalho Final de Curso. Tal processo instigante levou-me a desenvolver com eles um trabalho conjunto, olhando nossas aulas numa perspectiva de investigação-ação e colaboração. Assim, juntos, escrevemos um diário de aula descritivo e reflexivo sobre as aulas observadas e lecionadas. Pretendo, então, discutir modos de perscrutar os escritos diários de modo a avaliar como eles contribuem para a perspectiva colaborativa vivenciada durante o estágio, como também situar os aspectos metodológicos do trabalho de estágio e da pesquisa sobre ele. Dentre outros aspectos, procuro mostrar como, ao narrar os acontecimentos no diário, vivenciamos os sofrimentos do outro e comungamos a responsabilidade de educar matematicamente os alunos. Nesse processo, aspectos da identidade do futuro professor de Matemática vão se constituindo com as tensões da prática.
\end{abstract}

Palavras-chave: Formação de Professores de Matemática. Estágio Supervisionado. Trabalho Colaborativo. Investigação-ação. Pesquisa Narrativa.

\footnotetext{
* Uma primeira versão desse artigo foi publicada nos Anais do XI Encontro Nacional de Educação Matemática (ENEM) (18 a 21 de julho de 2013, Curitiba, PR), com o título "Perscrutando diários do estágio supervisionado da licenciatura em Matemática". A presente versão, no entanto, foi modificada e ampliada.

** Mestre em Educação pela Universidade Estadual de Londrina (UEL). Professor do Centro de Ensino e Pesquisa Aplicada à Educação (CEPAE) da Universidade Federal de Goiás (UFG). Endereço para correspondência: CEPAE/UFG, Campus II, Samambaia, Caixa Postal 131, CEP: 74001-970, Goiânia, GO, Brasil. E-mail: margonjunior@gmail.com.

**** Doutora em Educação pela Universidade Estadual de Campinas (UNICAMP). Professora da Faculdade de Educação (FE) da Universidade Estadual de Campinas (UNICAMP). Endereço para correspondência: FE/UNICAMP, Av. Bertrand Russel, 801, Cidade Universitária Zeferino Vaz, CEP: 13083-865, Campinas, SP, Brasil.E-mail: dione_paulo@uol.com.br.
} 


\begin{abstract}
Between 2008 to 2010, I received in my math classes prospective mathematics teachers whom were attending the Teaching Internship II, a course in preparation for a mathematics teachers program. As their classroom mentor teacher, I also was their Final Duty director. Working together with those student teachers, we approached a perspective of action research and collaboration in our teaching practice. Thus, we write a descriptive and reflective class diary, regarding to the observed and lectured classes. My intention is to discuss methods for peering the diary notes, so that, I can evaluate how this can contribute for the collaborative perspective experienced during the internship, as well as situate the methodological aspects of the teaching internship work and the research over it. Furthermore, in narrating the diary situations, I try to demonstrate how we experienced the difficulties of each other and how we share the responsibility for the mathematics education of the students. In this process, the identity aspects of the prospective mathematics teachers are constituted with the tensions of the practice.
\end{abstract}

Key-words: Preparation of Mathematics Teachers. Teaching Internship. Collaborative Work. Action Research. Narrative Inquiry.

\title{
1 Prólogo
}

Em cada um dos anos de 2008, 2009 e 2010 recebi $^{1}$ uma dupla de alunos de um curso de Licenciatura em Matemática ${ }^{2}$ da UFG em minhas aulas de Matemática, respectivamente num $1^{\circ}$ ano e $2^{\circ}$ ano do Ensino Médio e num $9^{\circ}$ ano do Ensino Fundamental. Recebi esses estudantes como supervisor de estágio, pois eu era o professor das turmas de educação básica do $\operatorname{CEPAE}^{3}$ na qual eles iriam realizar o Estágio Supervisionado em Docência e também os recebi como orientador do Trabalho Final de Curso (TFC) exigido por essa licenciatura (o qual versa sobre o estágio), pois, sendo o CEPAE uma unidade acadêmica da UFG, eu também pude assumir o papel de orientador. Estive assim, ao mesmo tempo, na posição de professor da Educação Básica e na de formador de professores.

Cada dupla me acompanhou em uma turma durante os três primeiros bimestres do ano letivo, passando pela fase de observação de minhas aulas $\left(1^{\circ}\right.$ bimestre), semirregência $\left(2^{\circ}\right.$ bimestre), na qual me auxiliavam em atividades com os alunos, mas não conduziam as aulas, e regência ( $3^{\circ}$ bimestre), na qual eram responsáveis por toda a condução das aulas, bem como pelo planejamento e avaliação. Desde o início, convidei-os a desenvolver uma prática colaborativa ao olhar para o ambiente da sala de aula numa perspectiva investigativa, de modo que estivessem presentes as seguintes ações: identificação de situações instigantes em relação ao processo de ensino e aprendizagem dos alunos; produção de informações sobre a prática

\footnotetext{
${ }^{1} \mathrm{O}$ uso da primeira pessoa do singular significa que as experiências aqui narradas foram vividas pelo primeiro autor, porém narradas a partir do olhar dos dois autores. O segundo autor é também orientador do doutoramento do primeiro.

${ }^{2}$ Curso oferecido pelo Instituto de Matemática e Estatística (IME) da Universidade Federal de Goiás (UFG).

${ }^{3}$ Centro de Ensino e Pesquisa Aplicada à Educação (antigamente chamado de Colégio de Aplicação da UFG).
} 
para melhor entendê-las; estudo e planejamento de ações a fim de abordá-las; desenvolvimento da ação planejada; realização de reflexão sobre o desenvolvimento da ação para, ainda em tempo, propor mudanças; e, por fim, uma reflexão geral sobre todo o processo.

Engajados no processo de ensino e aprendizagem e na investigação sobre ele, escrevemos um diário de aula conjunto, um caderno de notas feitas em colaboração, de caráter reflexivo a respeito de todas as aulas observadas e lecionadas durante as três etapas do estágio. Quando eu conduzia as atividades, os estagiários revezavam-se na escrita da descrição da aula no caderno e, por vezes, teciam alguns comentários. Em seguida, o diário me era entregue para que eu estabelecesse um diálogo com os relatos escritos e tecesse minha reflexão sobre a aula. Os papeis se invertiam quando a condução das aulas ficava sob a responsabilidade dos estagiários. Resumidamente, assim trabalhei com os licenciandos ${ }^{4}$ que recebi em minhas aulas de matemática: Bruna e Eva, no ano de 2008, Marciene e Daniel, em 2009, e Thieza e Siely, em 2010.

Esse processo formativo vivido por nós não era parte de uma pesquisa para uma tese, como é agora, ou nem mesmo uma pesquisa acadêmica. Apenas comecei a ver essa possibilidade quando, em 2011, após algumas discussões sobre o projeto de tese com o grupo de pesquisa do qual participo ${ }^{5}$, passei a vislumbrar a riqueza da formação já vivenciada, repleta de experiências, sobretudo para mim, e percebi a relevância do material guardado em cada um desses anos: os cadernos diários de cada dupla; os TFC (usualmente contendo uma proposta pedagógica, uma descrição da escola e do ambiente da sala de aula, os planos de aula e uma análise sobre as aulas lecionadas); alguns planos de minhas aulas; o Projeto Político Pedagógico do colégio e do curso de licenciatura; entre outros.

Dei-me conta assim que eu não apenas havia passado por esse processo formativo, mas também ele, o processo, havia passado por mim, acontecido para mim, marcando-me como profissional, tocando-me como professor, como supervisor, ou seja, havia vivenciado experiências (LARROSA, 1996) dentro desse processo de formação. Dessa forma, contar a história desse processo formativo é um modo de reconstituí-lo, de recriá-lo, de refazer a ação e, assim, de ir construindo meu caminho investigativo. Mas eu não podia contar sozinho, pois a vivência conjunta precisaria ser investigada com escrúpulo: iniciava minha perscrutação. Em janeiro de 2013, agendei um encontro com cada uma das duplas e levei a eles os cadernos de estágio. Selecionei alguns trechos específicos para lermos juntos e pedi que me ajudassem

\footnotetext{
${ }^{4}$ Os colaboradores autorizaram, por escrito, utilizar o seu primeiro nome.

${ }^{5}$ Grupo de Pesquisa em Práticas Pedagógicas em Educação Matemática (PRAPEM/UNICAMP).
} 
a contar aquela história. Para a leitura conjunta, levei também as pequenas narrativas (tal como a da seção 4, intitulada "Crônica de um erro anunciado") que eu já havia escrito com base nos cadernos. Pedi permissão, oralmente e por escrito, para áudio gravar aquele encontro e para utilizar os registros dos cadernos e do $\mathrm{TFC}^{6}$. Também solicitei que, futuramente, avaliem outras narrativas que escreverei durante essa pesquisa.

Embora eu mesmo tenha me referido a esses encontros como entrevistas, não me parece ser esse o termo adequado. Convidei-os a me ajudar a contar a nossa história e, com os cadernos em mãos, não me preocupei em ter perguntas a fazer, mas sim em ter coisas para tentar lembrar e contar. Busquei, junto a eles, aprender a contar uma história e procurar viver uma mútua construção de novas compreensões sobre a investigação que fizemos sobre o ensino e aprendizagem da Matemática. Tal como destacam Connelly e Clandinin (1990) sobre as portas que se abrem com a pesquisa narrativa, buscamos aprender a contar nossas próprias histórias, aprender a ouvir as do outro, aprender a contar junto. Foi também um momento de viver outras experiências: às vezes apenas nostálgicas; outras vezes como descobertas, como se algo já estivesse explicado desde lá, mas ninguém havia contado ainda; outras ainda como esquecimento, como silêncio, como um não lembrar; e, por vezes, de imaginar como foi que tal fato aconteceu mesmo.

Desse modo, partindo do âmago da experiência vivida, há o que contar acerca dos aspectos metodológicos vivenciados durante a formação e também dos relativos ao modo como pretendo investigar o vivido. Tratarei dessas questões nas duas próximas seções. Com isso, no presente artigo, pretendo: discutir aspectos metodológicos relativos ao uso de diários como instrumento de investigação, situando esse uso no processo formativo já referido; fazer uma primeira avaliação de como a escrita dos diários se relaciona com o processo de formação vivido e com as perspectivas investigativa e colaborativa que procurei trabalhar; e, ainda, apresentar uma narrativa mostrando como ela pode se configurar numa forma de compreensão do vivido, numa forma de compartilhar uma experiência referente a como negociávamos nossa identidade profissional - sempre um processo inacabado - ao nos implicarmos no processo de aprender a ser professor de Matemática.

\footnotetext{
${ }^{6}$ A possibilidade de identificação dos estagiários pela citação do TFC me levou a também solicitar autorização deles para utilizar esse documento. Ao citá-lo, farei referência somente ao primeiro nome do autor.
} 


\section{Investigando a própria prática}

Ao receber os alunos da graduação em minhas aulas, procurava construir um trabalho conjunto com eles, buscava desenvolver uma prática colaborativa. Ciente de que isso não podia ser imposto ao trio (eu, enquanto professor de Matemática da Educação Básica e supervisor de estágio, mais a dupla de licenciandos em Matemática), eu buscava inspiração nas características de um grupo colaborativo definidas por Fiorentini (2004, p. 59-60), das quais destaco as seguintes: num grupo colaborativo, "todos os envolvidos desejam crescer profissionalmente e buscam autonomia profissional"; há um "forte desejo de compartilhar saberes e experiências"; há momentos, durante os encontros, "para bate-papo informal, reciprocidade e comentários sobre experiências e episódios da prática escolar"; os participantes sentem-se "à vontade para expressar livremente o que pensam e sentem e estão dispostos a ouvir críticas e a mudar"; entre os participantes "não existe uma verdade ou orientação única para as atividades", pois cada um "pode ter diferentes interesses e pontos de vista, aportando distintas contribuições e diferentes níveis de participação"; são essenciais para o bom relacionamento do grupo "a confiança e o respeito mútuo"; os participantes "negociam metas e objetivos comuns, co-responsabilizando-se para atingi-los"; "há reciprocidade de aprendizagem".

São características que inspiravam o trabalho na medida em que eu procurava acolher os estagiários expondo a minha prática de professor como sujeita a críticas e colocando ao trio a corresponsabilidade pela educação matemática dos alunos da turma na qual se desenvolveria o estágio. Havia um excedente de visão ${ }^{7}$ (BAKHTIN, 2011) evidenciado quando se assistia à aula do outro, o que movimentava os escritos do trio. Com a preocupação de poder ser considerado um professor exemplo, mas também no intuito de melhorar a minha prática e até com um pouco de vaidade, eu me perguntava: $\mathrm{O}$ que será que eles podem ver em minhas aulas que eu mesmo não posso ver?

Entretanto, tratava-se de um grupo efêmero, com participantes que se encontraram por meio de uma disciplina (Estágio Supervisionado II) na qual cada um tinha um papel a ser cumprido, com alguns interesses comuns, mas também particulares. Os estagiários tinham seus interesses como acadêmicos de um curso e enquanto professores em formação inicial. Eu

\footnotetext{
${ }^{7}$ Segundo Bakhtin, essa expressão denota a possibilidade de enxergar o outro de fora e ver o que ele próprio não pode ver. Asssim, colocando-se no lugar dele, é possível dar-lhe um acabamento estético na medida em que nos identificamos com o outro na situação em que está. Após voltarmos a nós mesmos, esse acabamento estético completa-se num ato de produção de conhecimento sobre o outro, sendo possível reconfortá-lo e assistí-lo, se for o caso. O processo de identificação com o outro abre a porta para a produção de conhecimento.
} 
tinha preocupações como formador de professores e como professor da escola básica. Todos nós ali pretendíamos ensinar Matemática aos alunos, aprender a analisar a nossa prática para, em tempo, realizar mudanças em relação às aulas, pretendíamos viver um processo formativo em relação à profissão professor. Por isso, mesmo com objetivos comuns, os diferentes papeis de cada um dentro do trio e a efemeridade do grupo configuravam um processo colaborativo sempre em construção, nem sempre harmônico, algumas vezes tenso, mas negociado dentro dos limites de atuação pré-definidos pelos papeis institucionais de cada um.

Além do intuito de desenvolver uma prática colaborativa dentro de nosso trabalho, eu também procurava inserir características da investigação-ação. Assim, cada trio adotou, a seu modo, uma postura investigativa frente aos desafios do estágio. Postura que eu buscava em Elliott (1991, 2001), por exemplo, que coloca a importância da pesquisa-ação estar comprometida com a mudança curricular e com um processo de mudança e desenvolvimento prático no qual esteja presente uma "reconstrução conceitual teórica da prática" (ELLIOTT, 2001, p. 146), envolvendo "criação e testagem de soluções inovadoras para problemas educacionais" (ELLIOTT, 2001, p. 147). E também em Fiorientini (2004, p. 67), pois se os professores não são simplesmente o objeto da pesquisa, mas sim pesquisadores, então estamos próximos da acepção de pesquisa colaborativa defendida por ele, a qual

\footnotetext{
implica parceria e trabalho conjunto - isto é, um processo efetivo de co-laboração e não apenas de co-operação, ao longo de todo o processo investigativo, passando por todas as suas fases, as quais vão desde a concepção, planejamento, desenvolvimento e análise do estudo, chegando, inclusive, a co-participar do processo de escrita e de autoria do relatório final.
}

No processo formativo que vivenciamos, eu chamava os estagiários a olhar para a prática de ensino que realizaríamos como um ambiente instigante, a identificar situações, pensar sobre elas, efetuar ações a fim de melhor entendê-las, planejar ações a fim de modificá-las, intervir nas situações e refletir sobre os resultados dessa intervenção. Com isso, apareceram propostas diferenciadas de ensino, mudança de postura profissional, questões investigativas, trabalho em colaboração, reflexão sobre a ação, entre outras. Ou seja, nossas ações inspiravam-se em características da pesquisa-ação e da pesquisa colaborativa.

Como eu me preocupava em ter um olhar sistemático sobre a nossa prática de ensino, em nos colocarmos ao mesmo tempo como observadores e atores nesse processo, no início de cada ano eu negociava com a dupla um modo de registrar o que acontecia em sala de aula. Assim, procurávamos conversar sobre os seguintes itens: 1) Pensar e escrever sobre os objetivos de cada etapa do estágio e sobre as estratégias de ação; 2) Refletir sobre os acontecimentos em sala de aula para repensar a nossa prática enquanto professores; 3) 
Produzir relatórios durante a fase de observação, a fim de compreender a turma de alunos e de levantar questionamentos sobre o que acontece em sala de aula; 4) Com base nisso, pensar e propor ações para melhorar as aulas; 5) Definir a frequência e as características específicas do trabalho que envolverá o planejamento conjunto das aulas pelas quais os estagiários ficarão responsáveis e depois a realização delas na fase da regência; 6) Produzir relatórios de cada aula realizada durante a regência. Ainda, além do que ficaria registrado, planejávamos reuniões periódicas, normalmente quinzenais, para realizar uma discussão baseada nos escritos dos cadernos, complementando as conversas informais diárias que costumeiramente mantínhamos antes e depois de cada aula. Também no início de cada ano, procurava conversar sobre a corresponsabilidade pelo trabalho a ser feito com a turma de alunos.

Esses seis pontos foram gradativamente tomando relevância para mim com o passar dos três anos. Ou seja, eles não estavam prontos desde a primeira reunião com a primeira dupla. Eles estiveram mais ou menos presentes com as três duplas e somente hoje consigo sintetizar, nesses itens, como fui me identificando com esse trabalho de receber os futuros professores e procurar fazer uma investigação sobre a prática.

Bruna e Eva, por exemplo, após nossa primeira conversa com a proposta de registrar as aulas, decidiram utilizar um caderno cada uma para registrá-las. Em cada aula, uma delas ficava com essa responsabilidade. De tempos em tempos, normalmente quinzenalmente, eu também escrevia nos cadernos minhas reflexões a partir da leitura do que já estava lá e com base em minhas impressões sobre a vivência com a turma de alunos. Logo percebemos como ter dois cadernos dificultava as coisas, pois a sequencia da história das aulas pulava de um caderno a outro. Quando elas começaram a regência e eu fiquei com a responsabilidade de descrever as aulas, acabamos utilizando preponderantemente o caderno de Bruna. E elas também escreviam suas reflexões após minhas descrições. Foi um início um tanto confuso, pois nós três tateávamos aquele caminho novo. Porém, com o decorrer do processo, fomos compreendendo a importância do caderno diário para pensar sobre nossas próprias aulas e a sua utilidade para a escrita do TFC.

Já com Daniel e Marciene sugeri o uso de somente um caderno para o trio e procurei mostrar a necessidade de descrever a aula para, depois, escrever algum comentário, a fim de ter uma descrição para todas as aulas. Particularmente, eu tinha certa dificuldade com isso, pois começava a descrever e logo fazia comentários, dava sugestões, apontava críticas, indicava materiais. No entanto, ao final daquele ano, o caderno parecia estar organizado nesse sentido, até mesmo contendo cabeçalhos e títulos indicando os tipos de registros, as datas, 
entre outros. Hoje vejo como é mais fácil, nesse caderno, perceber onde estão as tentativas de compreender o que estava acontecendo na aula e onde estão os escritos descritivos. Mesmo misturando-se vez ou outra, e lembrando que pode haver uma tênue diferença entre esses tipos de registro, fica claro o uso de um ou outro tipo. As tentativas de compreender, as reflexões, ao meu modo de ver, são as escritas mais narrativas, pois a necessidade de encadear o enredo para compreender o que aconteceu era mais premente. Na descrição da aula, o que importa é mais o um depois do outro, ou seja, o que foi acontecendo na sequencia. Nos comentários e reflexões o um depois do outro é praticamente equivalente ao um por causa do outro ${ }^{8}$. Por isso chamo de narrativas a esses escritos, bem como aos relatos orais sobre eles durante as entrevistas com cada dupla, realizadas em 2013.

E com Thieza e Siely a estratégia se seguiu muito parecida, mas preenchemos dois cadernos seguidos. Do ponto de vista de investigar a prática, Thieza e Siely produziram muitos dados narrativos com os quais podíamos trabalhar como professores daquela turma. Nos escritos, como com a dupla anterior, era possível notar as diferenças entre tentar descrever e tentar compreender. Em todos os cadernos, o que se vê é uma longa conversa entre os estagiários e eu, momentos de concordância e também de discordância, elogios e críticas, aspectos sobre as quais ainda vou me deter na seção seguinte.

Por fim, investigar a nossa prática de ensino, usando o registro sobre as aulas como instrumento de investigação e compartilhar a responsabilidade pela educação matemática dos alunos, sem desrespeitar os diferentes papeis de cada um dentro do trio, eram, então, os principais aspectos norteadores desse processo formativo pelo qual passamos.

\section{Perscrutando diários}

\subsection{Como contar a história que vivemos?}

Passado já alguns anos desde essa vivência, vendo-me no papel de pesquisador do processo formativo pelo qual passamos, ponho-me a pensar em maneiras de olhar esse passado recente, seus indícios deixados nos escritos dos cadernos, ou seja, olhar para a história escrita nesses diários. Vejo-me, então, diante do problema de ter uma história para contar ou, melhor, de reescrever uma história e permitir a outros se relacionarem com ela.

\footnotetext{
${ }^{8}$ Expressões usadas por Ricoeur (2012, p. 245) ao comparar descrição e explicação: "Explicar por que algo aconteceu e descrever o que aconteceu coincidem. Uma narrativa que não consegue explicar é menos que uma narrativa; uma narrativa que explica é uma narrativa pura e simples".
} 
Reescrevê-la significa lidar com uma história contada nos diários, uma história longa, diária, descritiva e reflexiva, meio desencadeada de tão linear, até mesmo cansativa, pois muito cronológica, a qual preciso transformar em uma história compreensível. Mas não é só isso: é preciso dar a ela uma reorientação de modo a evidenciar o processo formativo pelo qual passamos, evidenciar como nos implicávamos ou não, nos identificávamos ou não com o aprender a ser professor. Então, além de lidar com o recontar, preciso procurar compreender o teor dos escritos desses diários, saber para quê serviam, para quem eram escritos, como eram escritos e por qual razão, como o trio lidava com eles, quando eles simplesmente não eram escritos, como neles se evidenciam ou não aspectos colaborativos, investigativos e formativos e sua relação com a nossa identidade profissional. Eis o que vou tentar trabalhar a seguir.

Talvez, aparentemente, recontar a história pareça ser um problema menor, pois bastaria ir contando, desde o começo, como encontrei Bruna e Eva, como foi a primeira aula, a segunda aula etc., passando por Marciene e Daniel até o momento da defesa do TFC de Thieza e Siely, colocando um ponto final nessa história. Isso parece ser o mais natural, o cronológico: com começo, meio e fim. Mas que começo? Que fim? Onde começa? Na primeira aula de Bruna de Eva? Ou naquilo que fiz antes disso e me levou a desenvolver o estágio desse modo? Talvez nem isso, pois eu não contei sobre minha graduação, sobre o meu estágio, não contei sobre minha educação básica, infância, família etc. Talvez isso não tenha mesmo importância. Será? Afinal, será que minha licenciatura foi das melhores a ponto de eu não ter extraído de lá uma crítica que me impulsionasse a fazer o que fiz no colégio em relação à formação de professores de Matemática? Será que a primeira vez que tentei fazer algo colaborativo foi durante o estágio? E será que depois da defesa de cada dupla eu não mais me encontrei com eles, como se nossa história conjunta tivesse de fato acabado? E, tendo eu tomado uma decisão sobre o início, o meio e o fim, seriam esses marcos, os mesmos escolhidos pelos estagiários?

Ao olhar para esse passado recente tenho a convicção de que "nada do que um dia aconteceu pode ser considerado perdido para a história” (BENJAMIN, 1985, p. 223). Meu dilema é não conseguir distinguir entre acontecimentos grandes e pequenos. É por isso que estou diante do instigante problema de ter uma história para contar.

Adianto, então, desde já: não é possível dar ao leitor a minha história como se fosse possível recuperá-la ou transmitir o que vivi. Meu objetivo é contar de modo a oferecer a mim mesmo uma maneira de me relacionar com aquilo que vivi. Ou seja, procurando novas relações, via linguagem, com minhas experiências, espero proporcionar ao leitor alguma 
experiência com o que vai ler. Desse ponto de vista, como se trata de narrar um processo formativo a partir do âmago da experiência que eu mesmo vivi e, devido a relação entre narrar e explicar (o "um depois do outro" e o "um por causa do outro"), vejo-me o tempo todo entrelaçando descrições e aproximações analíticas. Considero o presente texto uma análise narrativa de narrativas (FIORENTINI, 2012; GARNICA, 2009), pois não busco aqui uma narrativa generalizante rumo a uma explicação cabal; busco uma outra narrativa na qual transparecem minha subjetividade e a rede de sentidos que elaboro para as experiências com as quais quero lidar (GARNICA, 2010) e constituir ao narrar.

Como comenta Bolívar sobre a análise narrativa, a leitura deve proporcionar uma certa experiência e é a própria "trama argumental que determina quais dados devem ser incluídos, em qual local e com qual final” (BOLÍVAR, 2002, p. 18, tradução nossa). Não me interessa somente tomar a palavra e me dirigir a um interlocutor; minha ambição é "trazer para a linguagem e compartilhar com outrem uma 'experiência' nova", esse é o acontecimento completo no qual o "referente do discurso é rigorosamente contemporâneo de seu caráter de acontecimento e de funcionamento dialogal" (RICOEUR, 2010, p. 133).

Quando penso em reescrever a história dos cadernos, penso em um modo de contar as nossas experiências sem me preocupar muito se elas foram boas ou ruins, mas sim humanas, repletas das ambiguidades, incertezas e incompletudes características do processo vivenciado. Sem me preocupar com uma história totalizante, mas sim procurando "refazer a ação conforme a instigação do poema”, ciente de estarmos no mundo, sendo afetados por situações que nos levam a nos "orientar nele pela compreensão" como expectativa do fato de termos uma história para contar, uma experiência para compartilhar (RICOEUR, 2010, p. 133-138).

É uma tentativa de contar de modo a captar as experiências pelas quais passamos, o que é uma aventura complexa, como diz Garnica (2009, p. 84). E esse mesmo autor sugere uma chave para o meu caso: como escrevíamos no diário, o modo como escrevíamos, como transformávamos o vivido em escritos e os escritos em narrativas (ao refletir sobre as descrições, ao reelaborar os escritos para comporem o TFC, ao tentar contar outra vez a história durante a entrevista, por exemplo), parece-me ser uma chave para procurar experiências. Busco, então, ser "um contador de história, e a forma como essa história é narrada estará (ou poderá estar) contaminada com discursos que não são, via de regra, tomados como narrativas" (GARNICA, 2009, p. 92). Um esboço deliberado dessa tentativa é a compreensão buscada na última seção do presente artigo, como também o modo como procurei contar o meu percurso com os estagiários, desde o início desse texto. É uma espécie 
de contação de história na qual transparece minha construção teórica e metodológica. Isso acontece porque o fio condutor da minha investigação atual é o modo como vou refazendo as experiências pelas quais passei. Fazer uma revisão bibliográfica, propor um problema, estabelecer uma metodologia, ir a campo e colher os resultados é um encadeamento que não vivi. Parto das experiências que eu vivi, de dentro delas, e experiências humanas costumam ter outras lógicas. Não posso mudar o que vivi, mas - e aí consta a minha pesquisa narrativa posso olhar outra vez para o meu passado recente. Ele não muda, mas colocando outros olhares sobre ele, vou tentando ver coisas que não havia visto. Eu colho histórias, contadas por mim mesmo, e também pelos estagiários, e as conto outra vez, reorientando-as. Eis o modo que encontrei para responder às perguntas que me coloquei dentro da presente seção desse artigo.

Ao me reencontrar com Marciene, em janeiro de 2013, por exemplo, depois de alguns anos desde o estágio, a primeira coisa dita por ela, antes mesmo de iniciarmos a conversa, foi que nunca mais voltaria para a sala de aula, uma vez que havia passado por uma frustrante experiência em uma escola estadual, recebendo as turmas tidas como piores e trabalhando sem o auxílio de alguém mais experiente. Foi como se ela quisesse me contar o final história, continuar a história da qual participei. Depois do estágio, supõe-se a formatura, o ingresso no mercado de trabalho e, de certo modo, um final feliz, uma carreira promissora. Entretanto, nessa continuação, ela insere uma peripécia que reorienta a história no sentido de questionar a colaboração que vivemos, que só existe lá, onde vivemos, onde era possível, juntos, pensar e repensar a prática, tratar com cuidado e tempo os problemas e situações vividos com os alunos. Mas isso não continua na escola. Para contar a história dela, com certeza esse final tem um peso sobre tudo o que se passou antes, mesmo que não consideremos o final como consequência de tudo. Terminar a história dela com esse percalço profissional leva a um questionamento de todo o sentido de uma formação vivida, planejada, debatida congressos afora, preconizada teoricamente. Do mesmo modo que se pergunta para quê ensinamos Matemática, Marciene me fez perguntar para quê todo esse investimento em uma formação pautada na colaboração e na investigação sobre a prática. Onde mesmo ela ecoa?

Marciene e seus colegas, nos registros e nas entrevistas, contaram-me histórias as quais, hoje, reescrevo a meu modo. Meu modo nada mais é do que uma justificativa da reorientação que dou àquela história, uma justificativa da reorientação da atenção histórica (RICOEUR, 2010, p. 256). Trata-se de uma reorientação na qual procuro salientar o processo formativo vivenciado durante o estágio, compor um enredo no qual a colaboração e a 
investigação sobre a prática apareçam não necessariamente como heroínas da história ou demonstrando sua eficácia para a formação de professores. Ao invés disso, procuro um enredo no qual a busca por essas práticas esteja presente; mas sempre busca (já que era assim que eu me posicionava como formador de professores), caracterizada pela construção e desconstrução, pelas peripécias, percalços e, por vezes, até pela negação desse tipo de prática.

\subsection{O teor dos diários}

O que escrevíamos nos diários já seria, assim, uma reorientação para o observado? Não há experiência humana que não seja "mediatizada por sistemas simbólicos como a narrativa; há experiências que demandam narrativas, há uma estrutura pré-narrativa da experiência" (RICOEUR, 2010, p.128). Se uma experiência pode ser narrada "é porque ela já está articulada em signos, regras, normas: está, desde sempre, 'simbolicamente mediatizada'" (RICOEUR, 2010, p. 100-101).

Obervar e registrar passam por duas dimensões da mímesis: da "pré-figuração" para a “configuração" de uma narrativa (RICOEUR, 2010). Na primeira, há uma pré-compreensão comum do mundo em um ato interpretativo. No nosso caso, pré-figurava o fato de estarmos numa aula de Matemática, pré-figurava nossa compreensão comum sobre o que é esse lugar, o que se espera que nele ocorra, como se imagina que a aula começa, como é uma aula de Matemática, e registrar para tentar contar o que se observou na pré-figuração é responder ao próprio anseio de concordância temporal, no qual precisamos perceber o agenciamento das ações para realizar a configuração de uma história compreensível (RICOEUR, 2010). Milhões de coisas aconteciam numa aula, mas em poucas linhas podíamos narrá-las de modo que o trio pudesse se entender e continuar trabalhando. Esse era o objetivo último do caderno diário.

O processo de observar algo e registrar envolve uma mediação simbólica na qual é preciso selecionar, compreender o que acontecia na sala de aula situando o fato no factual, os fazeres dos alunos no contexto habitual de fazeres deles, os fazeres do professor no seu modo próprio de ser professor, a aula no conjunto de aulas, o conjunto de aulas nas práticas culturamente tidas como aulas de Matemática. Não que os registros seguissem esse esquema gradativo; o que quero ressaltar é que, ao escrever no caderno, uma seleção do presenciado era feita e registrada de modo a constituí-la para um outro. Não se trata efetivamente de uma reorientação, pois ainda não havia história, mas de uma primeira orientação, de uma destinação, pois havia um outro. Havia os leitores posteriores como o colega estagiário e o 
supervisor e orientador. Torna-se constituição por ser ponto de partida para os diálogos futuros, as discussões e as novas significações que se agregariam a partir daí e esse situar práticas em práticas nada mais é do que uma comparação, uma busca por similitudes, nem sempre explícita, mas presente no olhar. Trata-se de um ato configurante (RICOEUR, 2010), sobretudo quando o registro procura, além de descrever, fazer uma reflexão sobre o que aconteceu, pois aí o encadeamento dos fatos era tão importante quanto os fatos, por já ser um modo de tentar explicar os próprios fatos.

Mesmo ciente dessa mediação e dessa interpretação inerente à escrita, ainda ouso me perguntar: o que era escrito no diário? Ou melhor, qual o limite do seu teor? Seria uma espécie de "pensamento em voz alta" (YINGUER; CLARK apud ALVES, 2004, p. 224), de minha parte ou dos estagiários? Por serem escritos sob a "influência imediata de uma experiência” é possível afirmar que são "particularmente eficazes para captar as disposições de espírito e os pensamentos mais íntimos" (ALVES, 2004, p. 225) dos autores?

Nessa primeira escrita, resultante de observar e anotar no caderno de estágio, é preciso, em certa medida, descrever componentes referenciais (o local, as pessoas, o momento, a situação, a ocasião, o contexto) normalmente entrelaçados por componentes expressivos (impressões, pensamentos, opiniões, sensações, emoções, intenções, julgamento de valor etc.) (ZABALZA, 1994). Esses componentes não são aspectos objetivos, observáveis do mesmo modo por autores diferentes. Trata-se sempre de um processo reflexivo o modo como encadeamos os fatos, pois estamos sempre selecionando aquilo que nos toca, que nos faz sentido, que queremos passar para frente, ou seja, recontar; não há registro aleatório. "O que é re-significado pela narrativa é o que já foi pré-significado no nível do agir humano" (RICOEUR, 2010, p. 138) e é o que re-significamos para o outro, o leitor, o destinatário. Por isso a escrita muda quando mudamos de gênero, por exemplo, do caderno diário para o TFC, como conto na ultima seção. Estávamos num contexto específico, produzindo discursos em diferentes esferas (BAKHITN, 2011) de atuação: os diários na escola e o TFC na academia. Isso pesa sobre o modo como encadeamos a história, sobre a importância ou não, a pertinência ou não de uma experiência dentro dela. As histórias que contamos sofrem certo controle como prática discursiva e prática social (LAROSSA, 1996, p. 478).

Como, no nosso caso, o diário era compartilhado, ou seja, escrevíamos no caderno o que o outro iria ler logo a seguir, a escrita assumiu aspectos colaborativos. Mesmo com as relações de poder postas, ou seja, alunos da graduação e seu orientador de estágio, o que talvez justifique o fato da descrição dos estagiários apontarem poucas críticas às minhas aulas, 
mesmo assim, ao ouvir a história do outro, ao acompanhá-la eu acabo me identificando, pois os problemas e situações que o professor vive ali com os alunos logo estarão nas mãos dos estagiários. Ao acompanhar a história, posso imaginar fins. A dimensão coletiva aparece aí quando o diário servia para descrever informações as quais o professor não tinha acesso, tais como escrever sobre certo aluno que não participou da aula, dormiu ou ficou fazendo a tarefa de Geografia, anotar a dúvida de outro aluno que foi exposta somente ao relator, descrever algo ocorrido quando o professor estava escrevendo na lousa, de costas para a turma etc. Havia, por vezes, esse tom de delato. Porém, havia também sugestões para o prosseguimento da aula, para a continuação daquela história, ou seja, ao descrever a aula conseguimos imaginar fins possíveis, caminhos alternativos. Compartilhar o caderno permitia completar aquela história, ajudar o outro a continuá-la, colaborar para a consecução dos objetivos em relação à educação matemática dos alunos: nossa corresponsabilidade.

No caderno, contávamos histórias uns aos outros das aulas que assistíamos uns dos outros: uma prática social que me fazia perceber o modo como era identificado pelos estagiários e vice-versa, que dava sentido ao "mundo social, atribuindo identidades sociais aos outros" (PAMPLONA; CARVALHO, 2009, p. 213).

Há uma dimensão relativa ao outro para quem se escreve, pois lidávamos com a questão de escrever o que eu gostaria que o outro lesse sobre mim, sobre minha aula ou sobre o que eu penso sobre a aula dele. Aí jogam relações de alteridade que podem ser colaborativas. E é assim que eu percebo minha identidade e a dos estagiários. Não que agíssemos pautados numa falsidade, num querer parecer. De forma alguma. Mas minhas aulas com certeza seriam diferentes não fossem os estagiários presentes ali. As aulas dos estagiários também. Os escritos dos diários tinham um certo modo de ser e os escritos que compuseram, ao final, o TFC, tinham outro modo de ser. Há uma identificação e uma desidentificação ao mesmo tempo (LAROSSA, 1996): uma identidade do futuro professor na qual queríamos nos reconhecer (colaborativo, reflexivo, investigador) que é posta em questão pelas tensões da prática que, algumas vezes, configuravam histórias que não queríamos contar, pois não nos reconhecíamos nelas, não nos identificávamos nelas, entretanto, elas faziam parte da prática.

Com isso, meu critério ao olhar o processo formativo que vivi foi trazer ao papel os eventos nos quais a colaboração e a investigação sobre a própria prática pareciam acontecer sob alguma tensão, como se houvesse - e de fato havia muito por minha parte - uma vontade de que elas se desenvolvessem, porém, o seu desenrolar parecia mostrar como nos escapavam, onde elas estavam em construção ou desconstrução, na verdade ambos. Não se trata então de 
narrar uma história na qual a colaboração e a investigação apareçam como vilãs ou como a grande solução. Mas sim apresentar, em uma história singular, como nossas identidades foram sendo negociadas em meio às tensões da prática de investigar e colaborar ao ensinar.

Apresento a seguir uma narrativa que obedece a esse critério. Trata-se de um evento da dupla de 2010, Thieza e Siely. Para escrevê-la, baseei-me principalmente nos escritos dos cadernos, mas também nos áudios de nossas conversas de janeiro de 2013.

Por fim, não teci considerações finais depois de contá-la. Já há considerável interpretação colocada na narrativa e também na história que venho contando desde o início desse texto. O que vem a seguir é um modo de lidar com esse meu passado recente, é uma forma de compreendê-lo contando uma história a partir de um outro olhar que as compreensões teóricas já apresentadas me fizeram colocar sobre ele.

\section{Crônica de um erro anunciado 9}

Eupalinos não errou! Mas algum erro aconteceu naquela aula de Siely e Thieza. Hoje digo até erramos. Porém, talvez, naquela época eu não tenha tornado a situação realmente receptiva a conjugações da primeira pessoa do plural.

Dias desses li no jornal que, na construção de linhas do metrô paulista, engenheiros cometeram erros de cálculo provocando o desencontro de túneis que foram cavados em duas frentes diferentes ${ }^{10}$. Mas Eupalinos, aquele da ilha de Samos, há 2500 anos, exercendo uma função assemelhada ao que hoje chamamos engenheiro, já utilizava conhecimentos da geometria plana para resolver esse tipo de problema relacionado ao encontro de túneis. E não errava!

Está aí uma bela aplicação de semelhança de triângulos, sugeri a Thieza e a Siely.

Era essa a preocupação de Thieza em relação a uma das aulas em que ela abordaria esse conteúdo no $9^{\circ}$ ano no qual fazia o estágio. Ela não queria começar apresentando os casos de semelhança, mas sim com um problema envolvendo uma utilidade do conceito matemático. Dei a ela, então, o livro onde eu havia lido essa história de Eupalinos ${ }^{11}$. Ele não errou como os engenheiros do metrô, mas nós não éramos engenheiros, nem nos tornaríamos,

\footnotetext{
${ }^{9}$ Título inspirado no livro de Gabriel García Márquez, "Crónica de uma muerte anunciada".

${ }^{10}$ Notícia de 09 de setembro de 2007, da Folha de São Paulo (IZIDORO et al., 2007).

${ }^{11}$ Rosa (2004).
} 
éramos professor e futuros professores. Professores não erram - como dizia um velho professor meu - apenas se enganam.

A princípio, até desanimamos, pois não era um bom problema para começar esse conteúdo, já que exigia o conhecimento da semelhança para resolvê-lo, como se pode ver no exemplo de solução dada no Quadro 1.

1. Para atravessar um obstáculo (como uma montanha, por exemplo), dois grupos de trabalhadores vão cavar um
túnel: um, partindo do ponto A e o outro, do B. Assim, é necessário garantir que cavem numa direção de forma a
se encontrarem sobre AB; 2. Considerando a situação num plano, contorna-se o obstáculo traçando a poligonal
ADFGB. Assim, é possível descobrir o comprimento dos lados AC e CB do triângulo retângulo ABC; 3.
Conhecendo essas medidas, é possível construir os triângulos BGH e ADI, semelhantes a ABC, o que indica a
direção dos túneis.

$$
\begin{aligned}
& \text { Quadro } 1 \text { - O problema de Eupalinos } \\
& \text { Fonte: desenvolvido pelos autores }
\end{aligned}
$$

Passados alguns dias, Thieza veio com a ideia de utilizar exemplos em que a semelhança entre os triângulos fosse de razão 1, tentando trabalhar também com números sem casas decimais. Sugeri utilizar uma malha quadriculada para fazer o desenho, de modo a facilitar a obtenção das medidas. Isso foi dando substância à dinâmica de uma aula interessante. Estávamos em início de junho de 2010 ainda! Thieza e Siely lecionariam essa parte do programa somente no final de agosto. Havia tempo para pensar a respeito e propor uma boa aula, evitando possíveis erros.

Em julho, recebi delas todos os planos de aula, como costumeiramente solicitava aos estagiários, antecipadamente ao início da regência. Demorei a compreender o plano referente a essa aula com o problema do Eupalinos. Pensei que ele estava errado. Havia lá a proposta de utilizar uma maquete, de trabalhar em grupos e havia uma cópia do que seria entregue aos alunos, uma atividade intitulada "Colocando em prática", contendo orientações para realizar o procedimento de Eupalinos, mas não um problema e nem a história dos túneis.

Uma maquete! Surpreendi-me ao vê-la sobre a minha mesa: uma placa de isopor sobre a qual estava colada uma malha quadriculada, com o desenho de uma montanha e a indicação dos pontos pelos quais passaria o túnel. Thieza havia feito um modelo para pensarmos em como os alunos lidariam com aquilo. De cara, percebi algo que podia dar errado durante a aula. Peguei uma régua e tracei o túnel por cima do desenho da montanha: Está aí a solução do problema! - brinquei. A direção do túnel é esta. Claro! Os alunos estariam munidos de 
régua. $\mathrm{O}$ problema real era bem mais complexo que a simples maquete. Dizer a eles que não podiam traçar o túnel por cima da montanha, mas sim desenhar a poligonal, como no Quadro 1 , seria pouco convincente.

Um outro detalhe ainda nos incomodava, pois poderia dar errado durante a aula: seria uma tarefa complexa propor uma solução para tal problema. Os alunos ainda não dominavam a semelhança de triângulos; o problema seria ainda complexo mesmo se os alunos dominassem tal conceito. Ligar o problema a tal estratégia de solução não parecia algo simples. Por outro lado, eu pensava que simplesmente fazer os alunos repetirem o procedimento de Eupalinos seria pouco produtivo ou pouco desafiador.

Acabamos nos convencendo da não necessidade dessa aula desenvolver uma atividade de resolução de problemas, pois já haviam outras aulas planejadas segundo essa estratégia metodológica. E as futuras professoras argumentaram que, embora pretendessem apresentar o procedimento de Eupalinos na lousa, cada maquete seria um caso diferente do problema, pois as montanhas não eram iguais e nem os pontos para traçar o túnel. Ainda, mesmo duas maquetes iguais poderiam ter resoluções diferentes, chegando inclusive em outros triângulos semelhantes, devido a infinidade de poligonais possíveis. Essa aula se caracterizaria, então, por uma relação com a história da Matemática e pela atividade de exploração, por parte dos alunos, com o material construído.

Por fim, tínhamos uma hipótese sobre os possíveis erros dos alunos: o procedimento seria compreendido e realizado sem muita dificuldade, porém encontrar os triângulos semelhantes demandaria algum esforço, poderiam surgir erros de cálculo, erros de comparação de lados correspondentes e coisas do tipo. A análise dos erros dos alunos e o seu uso como estratégia para o ensino e aprendizagem da Matemática era, justamente, o tema do TFC de Thieza e Siely. Elas haviam identificado, em minhas aulas, como as discussões sobre os erros contribuíam para a aprendizagem dos alunos e, por essa razão, estudaram e trabalharam esse assunto em sua proposta pedagógica.

Compreendi, então, o nome da atividade sugerido por elas: "Colocando em prática". Essa folha era apenas um modo de guiar a produção dos grupos, orientando-os sobre o que fazer com a maquete, sobre as anotações a serem feitas e entregues às professoras. A atividade a ser feita seria apresentada oralmente por elas ao contar e mostrar a história dos túneis. Aquela atividade crescia em nossa estima.

Fui invadido, em minha sala, por uma série de maquetes, exatamente um dia antes da aula. Elas estavam lindas! Ao invés de um desenho de montanha, havia uma montanha! Sim, 
Thieza e Siely tiveram o cuidado de fazer montes de papel amassado, colados e pintados, se transformarem em belas representações de montanhas. Agora não havia como traçar o túnel com a régua... nos deparávamos com o mesmo obstáculo de Eupalinos! Como pôde ele não ter errado?

E a aula?

Os alunos estavam agitados e conversando. Talvez porque já estavam em grupos antes do início da atividade em grupo. Às vezes eu também me esqueço disso... A ideia é: coloque a turma em grupos somente quando for realizar a atividade. Se vai explicar algo antes, primeiro explique, depois forme os grupos. Se vai sistematizar ao final da aula, desmanche os grupos primeiro. [...]

Para que calcular o valor das hipotenusas? Resolvemos isso sem precisar delas. Com dois catetos, desenhamos tranquilamente as direções do túnel, o essencial para revolver o problema. (MARCOS, Caderno 2, 2010, p.12-13) ${ }^{12}$.

Meu registro é sintomático de como foi a aula. Sintomático porque foi um registro estranho comparado com meu modo usual de registrar. Descrevendo e comentando, coisa que fazia sempre de modo meio misturado, enchia tranquilamente cinco ou mais páginas do caderno para tratar de uma aula. Eu sempre tinha algo a escrever, a comentar, recheava as descrições com sugestões, com críticas, com falas dos alunos, dos futuros professores, enfim, procurava elementos para nossas conversas depois das aulas. Entretanto, o trecho transcrito anteriormente é quase tudo o que escrevi naquele dia: duas páginas, sendo que gastei quase uma inteira replicando o desenho dos triângulos semelhantes ${ }^{13}$. Eu travei! Nem cheguei a descrever o que de fato deu errado na aula. Esses comentários iniciais nem são erros, apenas detalhes em relação ao modo de conduzir a turma quando estão em grupos, como eu costumava sempre escrever. O que aconteceu depois é que foi o que há. Fiquei olhando e pensando em modos de ajudar a aula. Até mesmo a Siely interrompeu Thieza no intuito de esclarecer as coisas, mas não funcionou, os alunos já mexiam no material e não parecia mais possível salvar aquela aula depois do erro.

Após vários minutos de apatia na escrita do caderno, terminei meu registro assim: "Gostaria que vocês duas apontassem o que deu certo e o que deu errado nessa aula".

Passei a bola para elas! Não acredito! Eu também estava diante de tentar compreender o incompreensível. Seguir registrando seria tentar encadear os fatos num enredo coerente.

\footnotetext{
${ }^{12}$ Essa referência indica um trecho, escrito por mim, do segundo caderno diário da dupla do ano de 2010, Thieza e Siely. Assim como os estagiários, também utilizo o meu primeiro nome para fazer a referência.

${ }^{13}$ Bastante parecido com o do Quadro 1.
} 
Minha pré-compreensão da ação já estava munida da história anterior dessa aula. Com as peripécias discordantes que apareceram, os erros, eu já não conseguia contar a história.

Mas Thieza tentou:

A grande pergunta do momento, para mim, é: 'Por quê que não deu certo a aula?' ou 'Será mesmo que não deu certo?' [...] O começo da aula eu achei que estava falando muito rápido, pois estava com medo do tempo e o que me atrapalhou foi a conversa dos alunos, pois com isso tive que chamar a atenção deles várias vezes e eles não estavam participando da aula.

Não consigo entender o motivo pelo qual eu fiquei tão nervosa na hora de resolver o problema, pois eu estava ciente do que fazer e de como fazer e isso foi o que me atrapalhou. Quando eu marquei o caminho e percebi que estava errado, fiquei sem chão e a partir daí me descontrolei toda, atrapalhei a Siely e não consegui mais explicar direito o problema. Quando os alunos começaram a resolver e vi que estavam conseguindo fazer [o procedimento] eu fiquei mais tranquila (THIEZA, Caderno 2, 2010, p. 14-15).

E também Siely:

Achei que os alunos não conseguiram entender muito bem o problema e o porquê de resolvê-lo daquela forma proposta por Thieza. Só que eles começaram a fazer, pelo menos o desenho, da forma como ela explicou, assim, não consegui saber se entenderam, vamos ver a continuação da atividade na próxima aula.

Bom, havíamos comentado sobre o fato de ter colocado eles em grupos, antes de iniciar a atividade. Em relação ao que deu errado, nem sei o que falar, foi tão estranho que nem consegui ajudar a Thieza, na hora que percebemos que o desenho estava diferente do planejado. Mas é bom, pois isso nos ajudará a melhorar cada vez mais nosso planejamento, tentando sempre não cometer os mesmos erros. (SIELY, Caderno 2, 2010, p. 16).

Acontece que Thieza contou a história de Eupalinos tendo pouca atenção dos alunos e, por várias vezes, pediu energicamente a atenção deles. Por fim, utilizando um suporte quadriculado colado na lousa, fez e mostrou o procedimento como no Quadro 1, mas ele não funcionou. Os triângulos semelhantes davam diferentes direções e os túneis não se encontravam. Hesitou por alguns instantes, conferiu as razões entres as medidas dos catetos dos triângulos semelhantes, aparentemente corretas, e resolveu calcular a medida das hipotenusas. Como não registramos toda a lousa nesse dia, até hoje não sabemos onde estava o erro. É bem provável que tenha sido algum equívoco gráfico. Uma questão até pequena, mas no contexto daquele dia foi suficiente para desestruturar nossa segurança; sentíamos a aula ir-se sem rumo, mas não conseguimos fazer nada para retomar aquela nossa querida aula. Thieza pediu para os alunos trabalharem nas maquetes, pois algo no desenho dela não estava bom, mas na maquete funcionaria. Fomos então auxiliar os alunos nos respectivos grupos até que o sinal sonoro da escola colocou um ponto final naquela aula. 
Estávamos até comovidos depois da aula. Reinou um breve estranho silêncio entre o trio, enquanto descíamos as escadas rumo a minha sala de trabalho.

Thieza desculpou-se pelo erro. Isso, para mim, foi como ouvir uma outra história. Não sobre a tal aula. Mas uma nova história impactante em me fazer sentir o peso da responsabilidade por ter alimentado uma grande expectativa em torno daquela aula, por ter sugerido o tal do Eupalinos, por ter desde o começo - o começo mesmo, desde que comecei a receber estagiários da Licenciatura em minha aulas - procurado promover a reflexão sobre como foi a aula, identificar o que deu certo e o que deu errado, identificar os motivos; o quê, por vezes, pode também significar apontar quem errou e por que. Disse a Thieza que não devia desculpas a mim, nem a Siely, éramos um trio, afinal! Mas ela já havia pedido e isso fechava uma história antiga para mim. O que essa nova história me dizia, então, de modo lancinante, é que, por tudo isso, eu me configurava no outro a quem se devia desculpa. Desculpas a mim!? Mas não somos nós que trabalhamos em colaboração!? De quem foi erro? Errou Thieza, por não ter conseguido explicar o procedimento? Errou Siely, por não ter conseguido ajudar? Errei eu, por... por... por nos fazer procurar um culpado, procurar o erro? Por não ter orientado em relação a possíveis erros? Por não ter intervido na aula? Por ter nos conduzido num processo colaborativo onde eu sou a pessoa a quem se desculpar?

Por fim, a solução para o fato foi bem simples: retomar a explicação do procedimento na aula seguinte e seguir com a atividade, já que os alunos, conforme vimos nas histórias que contamos, estavam conseguindo realizar o proposto, apesar dos percalços.

Thieza e Siely contam essa história novamente no TFC:

A explicação do problema nos pareceu ter ficado um pouco confusa para os alunos, porém os grupos conseguiram iniciar sua resolução. Fizeram o desenho dos triângulos, o que nos mostrou o êxito obtido na explicação.

Ressaltamos que foi um erro ter dividido a turma em grupos, desde o início da aula, pois os alunos ficaram bastante agitados, conversando bastante. Deste modo, a explicação demorou mais do que o planejado e assim mais uma vez, não conseguimos atingir o objetivo que era, a partir da resolução do problema, fazermos a sistematização de Semelhança de Polígonos e o Teorema Fundamental de Semelhança, ficando para ser trabalhado na próxima aula. (SIELY, THIEZA, TFC, 2010 , p.56) ${ }^{14}$.

Parece que as coisas foram atenuadas no final... Acho que nós, professor e futuros professores, supervisor e estagiários, orientador e orientandos, mas também estudantes da análise de erros como estratégia para ensinar, não conseguimos encarar os próprios erros para

\footnotetext{
${ }^{14}$ Essa referência indica um trecho do Trabalho de Final de Curso da dupla.
} 
aprender. Na verdade, até encaramos, mas não soubemos explicitar isso no TFC e preferimos contar a história que foi contada. Bom, ao final, suspeito seriamente de Eupalinos. Não teria ele cometido algum errinho durante a escavação de túneis naquela época tão remota? Não haveria outras histórias sobre Eupalinos? Algum engano de historiador...

\section{Referências}

ALVES, F. C. Diário: um contributo para o desenvolvimento profissional dos professores e estudo dos seus dilemas. Millenium, Viseu, n. 29, p. 222-239, jun. 2004.

BAKHTIN, M. Estética da criação verbal. 6. ed. São Paulo: Martins Fontes, 2011. BENJAMIN, W. Sobre o conceito da história. In: BENJAMIN, W. Magia e técnica, arte e política: ensaios sobre literatura e história da cultura: obras escolhidas I. São Paulo: Brasiliense, 1985. p. 222232.

BOLÍVAR, A. B. “¿De nobis ipsis silemus?” Epistemologia de la investigación biográfico-narrativa en educación. Revista Electrónica de Investigación Educativa, Baja California, v. 4, n. 1, p. 01-26, fev. 2002.

CONNELLY, F. M.; CLANDININ, D. J. Stories of experience and narrative inquiry. Educational Researcher, Washington, v. 19, n. 5, p. 2-14, jun./jul. 1990.

ELLIOTT, J. El cambio educativo desde la investigación-acción. Madri: Morata, 1991.

ELLIOTT, J. Recolocando a pesquisa-ação em seu lugar original e próprio. In: GERALDI, C. M. G.; FIORENTINI, D.; PEREIRA, E. M. de A. (Org.). Cartografias do trabalho docente: professor(a)pesquisador(a). Campinas: Mercado de letras, 2001. p. 137-152.

FIORENTINI, D. Pesquisar práticas colaborativas ou pesquisar colaborativamente? In: BORBA, M. de C.; ARAÚJO, J. de L. (Org.). Pesquisa qualitativa em educação matemática. Belo Horizonte: Autêntica, 2004. p. 47-76.

FIORENTINI, D. À guisa de préfácio: a dor e a delícia de narrar e escutar histórias de professores. In: TEIXEIRA, I. A. de C.; PAULA, M. J. de; GOMES, M. L. M.; AUREK, W. A. (Org.). Viver e contar: experiências e prática de professores de matemática. São Paulo: Livraria da Física, 2012. p.1120.

GARCÍA MÁRQUEZ, G. Crónica de una muerte anunciada. Madrid: Mondadori Narrativa, 1987.

GARNICA, A. V. M. Notas sobre narrativa e educação matemática. In: LOPES, C. E.; NACARATO, A. M. (Org.). Educação Matemática, leitura e escrita: armadilhas, utopias e realidade. Campinas: Mercado de letras, 2009. p. 79-100.

GARNICA, A. V. M. Registrar oralidades, analisar narrativas: sobre pressupostos da História Oral em Educação Matemática. Ciências Humanas e Sociais em Revista, Rio de Janeiro, v. 32, n. 2, p. 20-35, jul./dez. 2010.

IZIDORO, A.; TOMAZ, K.; GUATELLI, C. Erro no metrô causa desencontro de túneis. Folha de São Paulo, São Paulo, 19 set. 2007. Cotidiano. p. C3. 
LARROSA, J. Narrativa, identidad y desidentificación. In: LARROSA, J. La experiência de la lectura: estudios sobre literatura y formación. Barcelona: Laertes, 1996. p. 461-482.

PAMPLONA, A. S.; CARVALHO, D. L. de. Comunidades de prática e conflitos de identidade na formação do professor de matemática que ensina estatística. In: FIORENTINI, D.; GRANDO, R. C.; MISKULIN, R. G. S. (Org.). Práticas de formação e de pesquisa de professores que ensinam matemática. Campinas: Mercado de Letras, 2009. p. 211-232.

RICOEUR, P. Tempo e narrativa. São Paulo: Martins Fontes, 2010.

ROSA, E. Como abrir um túnel se você sabe geometria. In: MINISTÉRIO DA EDUCAÇÃO.

SECRETARIA DE EDUCAÇÃO BÁSICA. Explorando o ensino da Matemática: artigos. Brasília: MEC, 2004. p. 158-162.

ZABALZA, M. A. Diários de aula: contributo para o estudo dos dilemas práticos dos professores. Porto: Porto editora, 1994.

Submetido em Agosto de 2013. Aprovado em Janeiro de 2014. 